\title{
Strukturerte selvmordsrisikovurderinger - en vitenskapsteoretisk analyse
}

\author{
Av Arne Thorvik
}

SELVMORD ER BESKREVET som en hard samfunnsvariabel, som tenderer mot å endres svært langsomt innenfor et geografisk område (Durkheim 1897/2000). Flertallet av mennesker som suiciderer har ikke kontakt med psykisk helsevern. Samtidig foreligger det et nærhetsetisk perspektiv, ved at helsepersonell har en etisk forpliktelse til å forsøke å forhindre at pasienter giennomfører selvmord.

Helsedirektoratet har utarbeidet Nasional faglig retningslinie for forebygging av selvmord i psykisk helsevern. Disse anbefaler risikovurderinger, basert på kunnskap om statistiske risikofaktorer for selvmord og et klinisk interviu (Helsedirektoratet 2008: 36).

Temaet har vakt debatt i fagmiliøet. I en kronikk publisert i Aftenposten i mai 2017 tok fagpersoner til orde for at nasionale retningslinjer bør revideres, og at risikovurderingen neppe er til nytte, men kan være til skade (Aarre et al. 2017).

Helsedirektoratet viste i brev av juni 2017 til at tematikken også tidligere har vært debattert i fagpresse, og siterte et tilsvar fra Nasjonalt senter for selvmordsforskning og -forebygging. Det heter her at selvmordsrisikovurderinger ikke først og fremst har som intensjon å eliminere all risiko for den enkelte. «Det ville være umulig og trolig også uetisk. Hensikten er å øke sikkerheten og kvaliteten for alle pasientene giennom spesifikke og målrettede tiltak» (Helsedirektoratet 2017).

\section{Målsetting og metode}

Denne artikkelen er å forstå som en vitenskapsteoretisk analyse av manualene som har vært kalt strukturerte selvmordsrisikovurderinger. Hvilket rasjonale er ment å ligge til grunn, og i hvilken grad kan dette begrunnes?

Metodologisk bygger artikkelen på medisinsk og vitenskapsteoretisk litteratur som er kjent for forfatteren, inkludert empiri fra eget doktorarbeid. Da artikkelen er en prinsipiell drøfting, er det ikke giort strukturelt datasøk.

Moderne vitenskapsteoretikere har tematisert at ingen faglig tilnærming, heller ikke en prinsipiell drøfting, er forutsetningsfri (Gadamer 1960/2007). Som beskrevet nedenfor, er denne artikkelen basert på at suicid er et multifaktorielt fenomen. Flere faktorer må foreligge for at suicid kan skje.

Med basis i en psykodynamisk tenkning tar artikkelen utgangspunkt i at formidling av egne suicidtanker til en utenforstående (behandler) ofte er en sårbar prosess. Det foreligger empiri som tilsier at det kan 

ikke tar høyde for ulikheter på individnivå, virker forstyrrende på relasjonen, og at kliniske vurderinger har en unik interpersonell-sensitiv kvalitet (Ægirsdottir et al. 2006).

For et hiemlig publikum bør det være av interesse at den norske psykiateren Christian Astrup allerede i 1975 presenterte en studie basert på 544 førstegangsinnleggelser av psykotiske pasienter ved Gaustad sykehus over en fireårsperiode, og konkluderte at statistisk («computer-calculated») og klinisk vurdering var omtrent jevnbyrdige når det gialdt å forutsi fremtidig funksjonsnivå hos disse pasientene (Astrup 1975).

Meehl har i en senere artikkel fremholdt at han fastholder så godt som all sin opprinnelige argumentasjon, og at vegringen mot bruk av manualer er irrasjonelt begrunnet (Meehl 1986). Debatten pågår fortsatt i internasjonal faglitteratur. Så sent som i 2009 viste en studie fra USA at nesten alle ( $98 \%$ ) av et utvalg psykologer ( $\mathrm{N}=491$, medlemmer av American Psychological Association) giorde bruk av kliniske interviuer for prediksjon, mens bare et mindretall (31 \%) anvendte manualer (Vrieze \& Grove 2009).

\section{Bruk av manualer for prediksjon av suicid - kort historikk} Det kan synes som det på 1970-tallet rådde noe optimisme når det gialdt prediksjon av suicid med statistiske metoder. Med utgangspunkt i 20 pasienthistorier indikerte en amerikansk studie at computere hadde større treffsikkerhet enn klinikere når det gialdt å forutsi selvmordsforsøk (Gustafson 1977). Noen år før hadde en prospektiv studie, basert på 361 pasienter med psykotisk lidelse, konkludert med at bruk av skalering, demografiske og diagnostiske data tenderte mot signifikant prediksjon. I denne studien nevnes imidlertid problematikken rundt spesifisitet og sensitivitet, videre at suicid prinsipielt er vanskelig predikerbart ved at forekomsten i utgangspunktet er lav, og ved at utkommet av et selvmordsforsøk kan være tilfeldig (Shaffer 1974).

I ettertid har mange publikasjoner vist til denne typen innvendinger. Pokornys studier fra 1980-tallet er ofte sitert i faglitteratur: Med basis i et stort antall sykehusjournaler $(\mathrm{N}=4800)$ til en høyrisikogruppe

\section{Bruk av struktu-} rerte selvmordsrisikovurderinger i dagens Norge har ikke prediksjon som primær intensjon. (krigsveteraner) lyktes en forskergruppe (via logistiske regresjonsanalyser) å predikere $35 \mathrm{av}$ 63 suicid over en femårsperiode. Dette var imidlertid på bekostning av et svært stort antall falskt positive anslag $(\mathrm{N}=1206)$. "We concluded that identification of particular persons who will commit suicide was not possible at any practical or useful level, because of the relative rarity of this behavior (low base rates) and the imprecision (low sensitivity and specificity) of

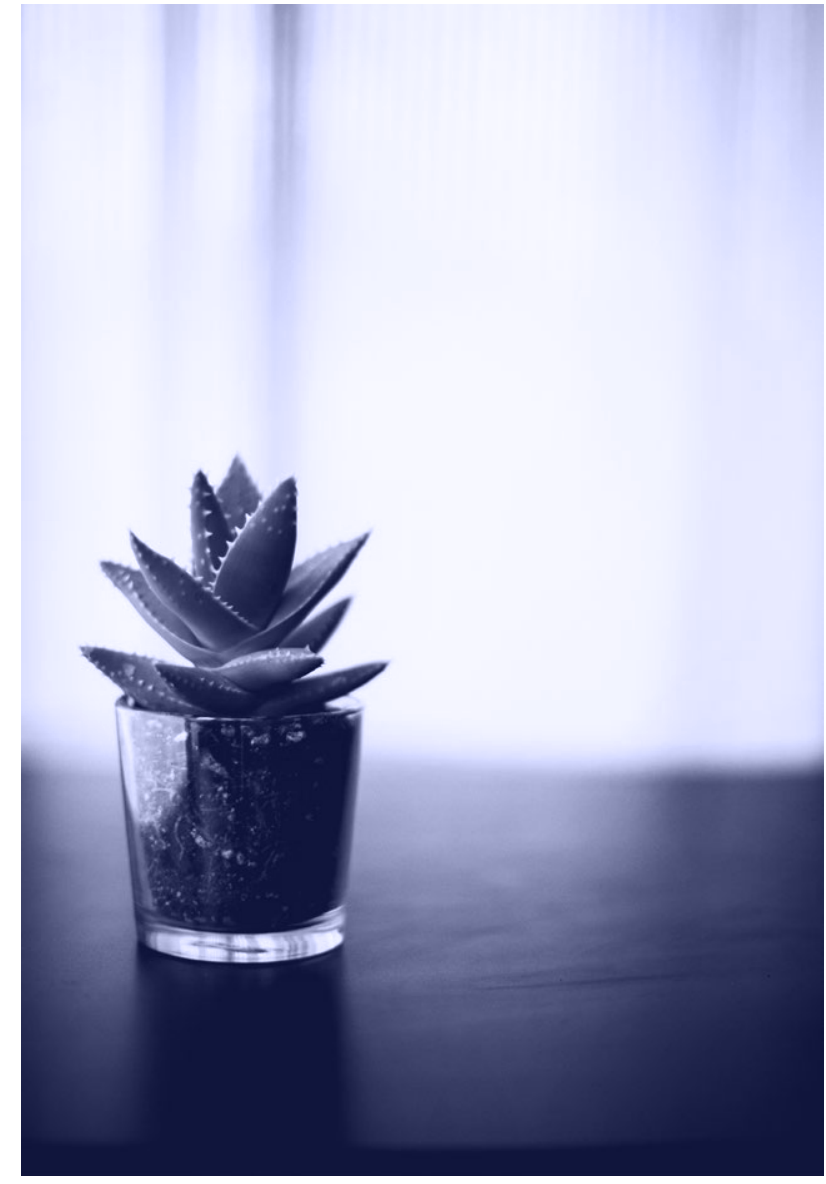

our predictive scales, instruments, and items» (Pokorny 1993: 2).

Det merkes at noen etterfølgende studier ser et visst potensial for prediksjon. Basert på journalene til 112 innlagte pasienter som hadde suicidert, isolerte Powell og medarbeidere fem prediktive faktorer (suicidplaner, tidligere selvmordsforsøk, psykisk lidelse, realitetsbrist og familiært suicid). Modellen antyder at 30-40\% av de som har samtlige faktorer innfridd vil suicidere. Imidlertid var det ekstremt sjeldent at alle faktorer var til stede. Også Powell viser til at det overveldende antallet av falskt positive anslag tilsier at modellen ikke er klinisk anvendbar (Powell 2000).

Retrospekt er Pokornys studier å anse som konklusive, ved at de tydelig demonstrerer at prediksjon av selvmord og selvmordsfors $ø$ k hos enkeltpersoner ikke er mulig, ved at alle kjente vurderingsinstrumenter har for lav sensitivitet og spesifisitet, og på grunn av den lave basalraten som selvmord har.

\section{Prediksjon versus vurdering}

Som nevnt innledningsvis, samstemmer også Helsedirektoratet i at «selvmord ikke kan predikeres på individnivå» (Helsedirektoratet 2017). I et nyere 
debattinnlegg i Tidsskrift for Den norske legeforening vises det til at man må nyansere mellom vurdering av selvmordsfare på kort og lang sikt, og at dagens selvmordsrisikovurderinger brukes til å iverksette beskyttende tiltak overfor pasienter med selvmordsproblematikk (Ekeberg \& Hem 2017).

Nettopp dette er et kjernepunkt. Bruk av strukturerte selvmordsrisikovurderinger i dagens Norge har ikke prediksjon som primær intensjon, men forsøker å identifisere en gruppe individer som er mer risikoutsatt enn andre i en gitt situasjon og innen et gitt tidsrom, for dermed å kunne intervenere overfor disse på en hensiktsmessig måte.

Av den grunn er vurdering av selvmordsrisiko å forstå som et transaksjonelt fenomen og en intervension i seg selv: Idet man vurderer selvmordsrisiko, intenderer man også å påvirke pasienten i retning av å redusere risikoen (i den grad det er behandlingsmessig mulig, og forutsatt at man har tilstrekkelige kunnskaper og kliniske ferdigheter). Dette står i motsetning til andre fagområder, der prediksjon er den umiddelbare hensikt (som innen meteorologi og astronomi).

\section{Suicid som multifaktorielt fenomen}

Faglitteratur beskriver suicid som multifaktorielt. I en drøfting av «suicide causation» brukes formuleringen «a complex web of many different factors» (O'Carroll 1993).

Man kan likevel diskutere om det gir mening å skille mellom «utløsende» og «fra-før-tilstedeværende» (fasiliterende) faktorer. Distinksionen forekommer i medisinsk faglitteratur (Rothman et al. 2008). I forbindelse med doktorgradsarbeid interviuet forfatteren av denne artikkel 40 informanter med selvmordsproblematikk. Av de tyve ikke-psykotiske informantene beskrev to at økonomiske vansker var utløsende, én viste til arbeidsudyktighet, to til brudd med

Det synes likevel åpenbart at suicid fortsatt er et multifaktorielt fenomen. partner, mens tre så egen depresion som utslagsgivende. De ovrige tolv hadde en subjektiv opplevelse av at suicidal prosess hadde vært betinget av mange faktorer. Tilsvarende beskrev tretten av de til sammen tyve informantene en psykotisk motivasjon, som plutselig innsettende hallusinose eller psykotisk tankeinnhold. De øvrige beskrev en subjektiv nederlagsfølelse, uten å kunne peke på en distinkt faktor. Noen informanter poengterte at suicidalitet kunne oppleves annerledes fra gang til gang, og at motivasionen kunne være tilsvarende ulik (Thorvik 2011).

Distinksionen mellom utløsende og fasiliterende faktorer kan være relevant i en drøfting av suicid, ved at en utløsende faktor ligger svært nær i tid. Det synes likevel åpenbart at suicid fortsatt er et multifaktorielt fenomen. Det kan skje at en person (A), uten andre kjente risiko- faktorer, suiciderer etter å ha giort feiltrinn som medfører negativ medieomtale. En hypotetisk kontrafaktisk setning synes å gi mening: "Hvis A ikke hadde giort feiltrinn som førte til medieomtale, ville suicid ikke ha skjedd.» Det er likevel åpenbart at As psykologiske konstitusion var medvirkende, da negativ medieomtale oftest ikke fører til suicid. Som referert doktorarbeid viser, vil suicidalitet kunne oppstå hos en person (B) etter uventet samlivsbrudd. Igjen må personens (Bs) psykologiske konstitusion ha betydning, idet brudd med partner for et flertall ikke impliserer selvmordsproblematikk.

Dette understreker igien viktigheten av en individuell tilnærming, som vektlegger verdigrunnlag og psykologisk konstitusjon hos den enkelte.

«Faktorer» kan nyanseres videre. Engelsk filosofi har ofte giort en distinksjon mellom motiver («motives») og årsaker («causes») (Ryle 1949/199o). Motiver (som også kan kalles grunner, «reasons») kan forstås som noe som «trekker» mot en handling, mens årsaker i større grad «skyver» (og dermed indikerer en ukontrollert prosess eller en determinisme). I sin forståelse av suicid har psykodynamisk tradisjon pekt på motiver (med ulik grad av bevissthetsnivå), så som ønske om gienforening med avdøde eller en type guddom («merging fantasy»), aggresion mot seg selv («fantasy of self-punishment») eller gienlevende («revenge fantasy») (Hale 1991). Klinisk psykiatri har i større grad tatt for seg årsaker, som hallusinose eller depresion. Det foreligger empiriske studier som viser at selvmordstruede ser denne distinksjonen, og selv tenderer mot å vektlegge motivene (grunnene) for egen selvmordsatferd, mens behandlerpersonale ofte baserer sin forståelse av suicidalitet på årsaker (Michel 1994).

Distinksjonen er klinisk viktig, ved at man i psykoterapeutiske samtaler vil kunne avdekke motiver som medvirker til suicidalitet, og forsøke å bidra til pasientens refleksion rundt egne motiver. Derimot kan årsaker som hallusinose eller depresjoner tidvis kreve andre medisinske tiltak, som hospitalisering eller medisinering.

\section{En epidemiologisk modell}

Generelt synes medisinske fenomener (også somatiske) multifaktorielle. Epidemiologisk er dette beskrevet i en såkalt «Pie Chart Model». Kiente faktorer er navngitt som «A», «B», «C» et cetera, mens ukjente faktorer er kalt «U». Alle faktorer (kjente og ukjente) må være til stede for at et fenomen skal inntreffe. Dersom man har fokus på og lykkes i å eliminere én kjent faktor, vil man teoretisk kunne forhindre at et fenomen inntreffer (Rothman et al 2008: 8). En slik modell har siden 1990-tallet vært hevdet innen suicidologi (O'Carroll 1993).

Dagens strukturerte vurderinger inkluderer kjente statistiske risikofaktorer for suicid (fremkommet ved studier av grupper av suicidale) og et klinisk interviu. Som statistiske risikofaktorer nevnes psykisk lidelse, 


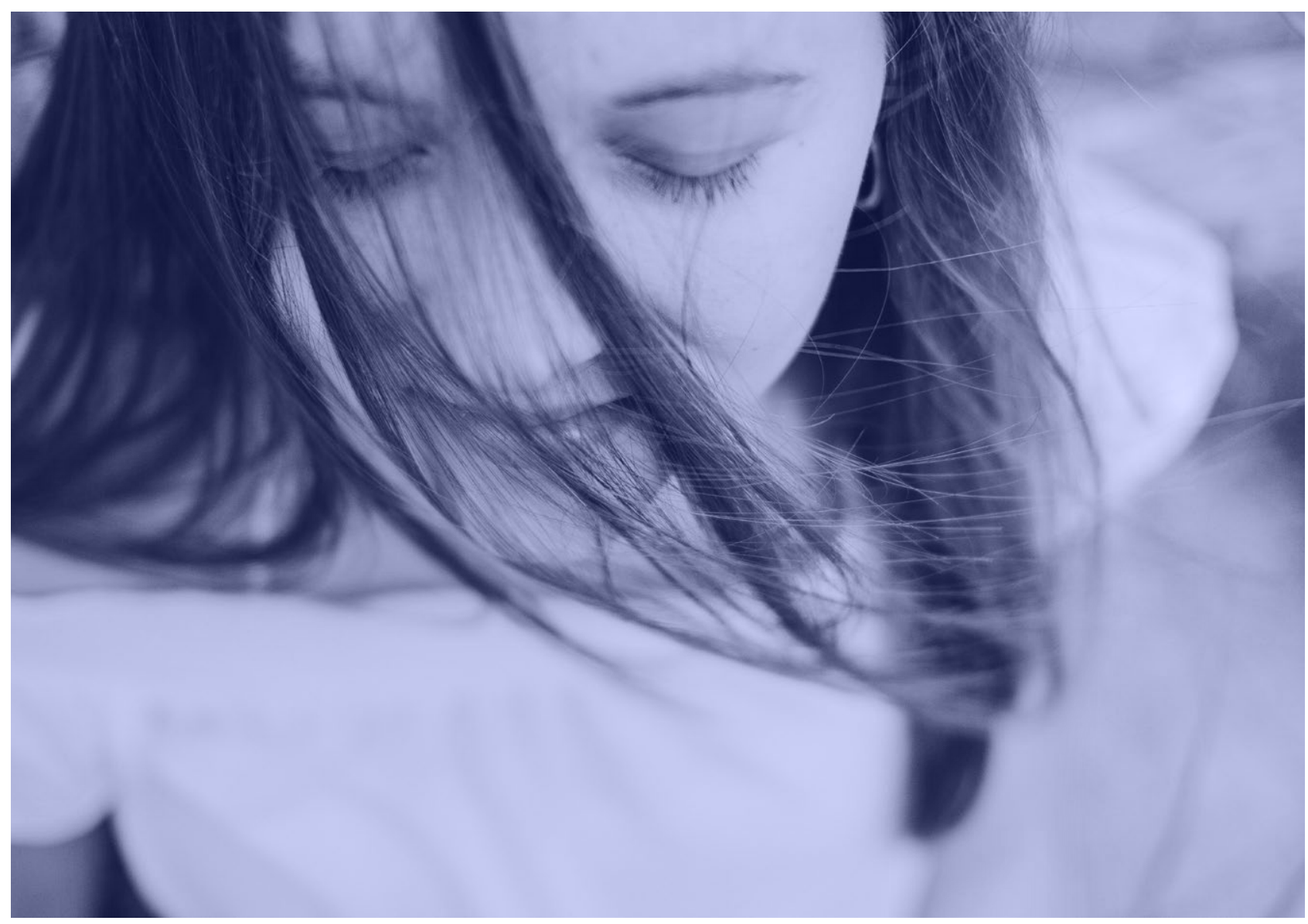

rusmiddelavhengighet/rusmiddelbruk, brudd i relasion (inkludert utskrivning fra døgnenhet), selvmord i familien, tap av selvaktelse/ærekrenkelse (media) og manglende nettverk.

Videre anfører norske retningslinjer at det bør stilles spesifikke spørsmål til pasienten om selvmordstanker og -planer, om man har imperative hallusinasjoner, håpløshet eller dødsønske, og hvorvidt man har tilgang til våpen eller farlige medisiner i hjemmet (Helsedirektoratet 2012: 37).

Å kunne avverge et multifaktorielt fenomen som suicid ved å modulere én faktor synes lovende, men man kan også ha innvendinger mot metoden. Disse er diskutert nedenfor.

Innvending: Suicid er en villet, ikke årsaksstyrt handling Det kan diskuteres hvorvidt en modell som primært er utviklet for å beskrive somatiske (biologiske og mekaniske) fenomener lar seg applisere på suicid, som umiddelbart synes å inkludere et element av handlefrihet («fri vilje»). I engelsk litteratur er dette kjent som «The Free Will Objection».

Hvorvidt suicid bør forstås som en determinert (årsaksstyrt) eller villet handling, har ofte vært tema i en filosofisk drøfting av suicid. Med basis i eget doktorarbeid finner artikkelforfatteren at en suicidal prosess kan nå et stadium der individet ikke lenger opplever å ha styring. På dette stadium kan selvmord sammenliknes med et somatisk fenomen. Historisk har sammenlikningen også vært giort, eksempelvis av den skotske filosofen David Hume på 1700-tallet (Hume 1783/1995). Aktuell tilnærming vil da være å forsøke å modulere årsaker, så som psykisk lidelse eller virkelighetsforvrenging.

Den beskrevne distinksjonen mellom motiver og årsaker impliserer at enkelte selvmordsfaktorer ikke er «mekaniske», men påvirkbare av individet. Man vil da kunne argumentere med at refleksion rundt motiver kan være tema i terapeutiske samtaler, med intension om at pasienten oppnår et metaperspektiv på egen dynamikk.

Modellen er derfor fortsatt klinisk anvendbar, også for pasienter som befinner seg på et tidlig stadium i en suicidal prosess.

\section{Innvending: Andre faktorer er utslagsgivende}

Det er verd å merke seg at det ikke synes å være konsensus om hvilke risikofaktorer som bør inkluderes i en 
strukturert vurdering. Eksempelvis nevner en svensk fagbok også faktorer som angst, søvnvansker, nevrologisk sykdom, smertetilstand og voldstilbøyelighet (Runeson et al. 2012: 110).

I vår tid er det tematisert i faglitteratur at mennesker som har vært utsatt for fysiske og psykiske overgrep har en høyere suicidrisiko. For et enkeltindivid kan slike faktorer være den dynamikken som «reelt ligger til grunn» (også der vedkommende har andre og kjente risikofaktorer).

Dette er en vektig innvendig, og viser viktigheten av en individuell tilnærming, som åpner for andre faktorer og annen dynamikk på individnivå enn den som fremkommer av en standardisert manual.

Enn videre viser eksemplet betydningen av en varsom tilnærming. Det bør være vel kjent at et fokus på traumer i fortid kan ha til følge at fortrengt materiale bevisstgiøres, og da øke suicidalrisiko.

\section{Innvending: Noen faktorer kan være beskyttende}

Faglitteratur opplyser at noen beskrevne risikofaktorer (iallfall temporært) også kan virke beskyttende hos enkeltindivider. Generelt gir psykotisk lidelse øket risiko, og det er vist kasuistisk at suicidforsøk kan være motivert av hallusinose (Thorvik 2011). Derimot angir studier at aktive sykdomsfaser med vrangforestillinger og hallusinasioner faktisk kan redusere risiko (Hawton et al. 2005: 18-19). Om kliniske depresjoner har det tradisjonelt vært anført i faglitteratur (og artikkelforfatteren har erfart) at disse kan gi motorisk hemning som vanskeliggiør suicid, og at bedring er derfor en sårbar fase (Kringlen 1982: 390). Videre vil enkelte

En god vurdering forutsetter at pasienten tor å åpne seg. Dette setter også krav til tidsbruk. pasienter kunne bruke rusmidler for å dempe akutte suicidtanker. Igien viser dette viktigheten av en varsom og utforskende tilnærming, rettet mot en dybdeforståelse av reell dynamikk hos

enkeltindividet, herunder statistiske risikofaktorer som i perioder (paradoksalt) kan virke beskyttende. Det merkes at også beskyttende faktorer inngår i en strukturert selvmordsrisikovurdering.

Innvending: Relevante faktorer holdes skjult for behandler Innvendingen er presentert innledningsvis i denne artikkelen. Suicidalitet er et privat tema, relatert til private faktorer. Personalet som foretar en strukturert selvmordsrisikovurdering kan være uten tidligere behandlingsrelasion til aktuelle pasient.

Psykodynamisk litteratur har pekt på viktigheten av å skille mellom suicidfantasier og suicidintensioner. Det må skapes trygghet i den terapeutiske relasjonen, slik at pasienten faktisk tør snakke om tematikken (Gabbard
1994). Et eksempel er suicidalitet relatert til overgrepshistorie, der det bør være en klinisk erfaring at det ofte foreligger psykologisk motstand, både når det gielder å utforske egen dynamikk (introspeksjon), og formidle denne til en utenforstående behandler.

Fenomenet psykologisk motstand er en relevant innvending, og illustrerer en begrensning ved strukturerte selvmordsrisikovurderinger. En god vurdering forutsetter at pasienten tør å åpne seg. Dette setter også krav til tidsbruk. At denne typen vurderinger ikke sjelden brukes til å ta stilling til tvangsinnleggelse eller andre tvangstiltak, kan også bidra til å øke psykologisk motstand.

Selv i en travel klinisk hverdag bør man forsøke å unngå situasjoner som tilsvarer beskrivelsen nedenfor, hentet fra en psykodynamisk orientert artikkel:

In a busy emergency department, patients are interrogated in a hurried manner by a physician, or a medical assistant, who will fire a number of questions at them regarding their history of suicidal behavior and mental state, and maybe hasten them through a check-list of suicide-risk factors. This examination is likely to be carried out in a half hour or less, to permit a disposition either to admit (often by involuntary hospitalization), to refer to the outpatient department, or to send the patient home. Typically, at the end of this procedure patients feel they have been impersonally processed and given little opportunity to contribute to any perspective on what actually happened (Michel et al. 2002: 3).

\section{Oppsummering}

Flere studier har vist at prediksjon av suicid på individnivå med dagens metodikk ikke er mulig. Dette er heller ikke den primære intensjonen ved bruk av strukturerte selvmordsrisikovurderinger. (Prinsipielt kan man ikke utelukke at man i fremtiden kan utvikle mer nøyaktige verktøy. Et forsøk på gradering av suicidtanker og -atferd (varighet, frekvens, kontroll, beskyttende faktorer) er giort av Posner (Posner et al. 2011)).

Som argumentert ovenfor, kan man vitenskapsteoretisk hevde at en giennomgang av kjente risikofaktorer har et rasionale, ved at man med sannsynlighet (men ikke med sikkerhet) treffer en faktor som inngår i en suicidal prosess for et individ, og da kan sette inn behandlingstiltak i den hensikt å forhindre at suicid skjer.

Dagens strukturerte vurderinger inkluderer statistiske risikofaktorer som er fremkommet ved studier av grupper av suicidale. Også på individnivå bør det derfor være en statistisk sjanse for å treffe en faktor som medvirker til suicid. Meehl og medarbeidere uttrykker dette slik: «A common anti-actuarian argument, or misconception, is that group statistics do not apply to single individuals or events. The argument abuses basic principles of probability. Although individuals and events may exhibit unique features, they typically share 
common features with other persons or events» (Dawes, Faust \& Meehl 1989: 243).

Selv om et rasionale foreligger, må man se beskrevne innvendinger og begrensninger ved metoden. I møtet med enkeltpasienter bør man vektlegge klinisk inntrykk og nyanser, og være oppmerksom på fenomenet psykologisk motstand. I beste fall vil man kunne avdekke individuelle faktorer som kan inngå i en suicidal prosess hos den enkelte.

Det bør understrekes at det ikke trenger å være noe motsetningsforhold mellom en individuell klinisk vurdering og bruk av strukturerte verktøy. Som beskrevet i faglitteratur, vil det i akuttpregede situasjoner ofte være åpenbart hvilke faktorer som er umiddelbare eller utløsende (Ekeberg \& Hem 2017).

Et ytterligere argument for dagens bruk er at selvmord og selvmordsatferd erfaringsmessig gir store emosjonelle reaksjoner hos nærstående og behandlere. Også av hensyn til disse bør det være gunstig at risikofaktorer er forsøkt kartlagt på en standardisert måte.

Artikkelforfatteren er derfor av den oppfatning at strukturerte selvmordsrisikovurderinger har et rasjonale som et behandlingsmessig tiltak. Bruken bør opprettholdes, iallfall inntil klar empiri måtte tilsi noe annet.

Et kvalitativt middel må likevel ikke bli et kvantitativt mål. Begrensninger som psykologisk motstand og individuelle faktorer tilsier at man fremfor kvantitet bør vektlegge kvalitative vurderinger som indikerer relevante behandlingstiltak.

Levert: 08.12.17 - Revidert: 08.03.18 - Godkjent: 24.04.18

\section{REFERANSELISTE}

Astrup, C. (1975). Predicted and observed outcome in followed-up functional psychoses. Biological Psychiatry, Vol. 10 (3): 323-328.

Binswanger, L. (1944/1994). Der Fall Ellen West. I: Ausgewählte Werke, 4: 73-209. (Engelsk oversettelse: The Case of Ellen West. I: R May, E Angel \& HF Ellenberger (eds). Existence. New York: Basic Books, 1958).

Busch, K.A., Fawcett, I., \& Jacobs, D.G. (2003). Clinical correlates of inpatient suicide. The Journal of Clinical Psychiatry, 64: 14-19.

Dawes, R.M., Faust, D., \& Meehl, P.E. (1989). Clinical versus acturarial judgment. Science, Vol. 243: 1668-1674.

Durkheim, E. (1897/2000). Selvmordet. Oslo: Gyldendal.

Ekeberg, Ф. \& Hem, E. (2017). Kan vi forebygge selvmord? Tidsskr Nor Legeforen; 137: 1680-81.

Gabbard, G. (1994). Management of Countertransference with Borderline Patients. Washington D.C: American Psychiatric Press.

Gadamer, H.G. (1960/2007). Wahrheit und Methode. Berlin: Akademie-Verlag.

Gustafson, D. et al. (1977). A probabilistic system for identifying suicide attempters. Computers and Biomedical Research, 10: 83-89.

Hale, R. 1991. Suicidal acts. I: Jeremy Holmes (red): Textbook of psychotherapy in psychiatric practice. Edinburgh: Churchill Livingstone.
Hawton, K. et al. (2005). Schizophrenia and suicide: systematic of risk factors. British Tournal of Psychiatry, 187: 9-20.

Helsedirektoratet. Selvmordsforebygging og selvmordsrisikovurderinger. Brev fra Helsedirektoratet til de regionale helseforetakene, datert 22. juni 2017, referanse 17/15164-1.

Hume, D. (1783/1995). Essay on suicide. In: Four dissertations and essays on suicide and the immortalily of the soul. Indiana: St. Augustine's Press.

Isometsa, E.T. et al. (1995). The last appointment before suicide: Is suicide intent communicated? The American Tournal of Psychiatry; 152 (6): 919-922.

Kringlen, E. (1982) Psykiatri. Oslo: Universitetsforlaget.

Meehl, P.E. (1954). Clinical versus statistical prediction. Minneapolis: University of Minnesota Press.

Meehl, P.E. (1986). Causes and effects of my disturbing little book. Tournal of Personality Assessment, 50 (3): 370-375.

Michel, K., Valach, L. \& Waeber, V. (1994). Understanding deliberate self-harm: The patients' views. Crisis 15 (4): 172-178.

Michel, K. et al. (2002). Discovering the truth in attempted suicide. I: American Journal of Psychotherapy, Vol. 56, No. 3: 424- 37.

O'Carroll, P. (1993). Suicide causation: pies, paths, and pointless polemics. Suicide and Life-Threatening Behavior, Vol. 23(1): 27-36.

Pokorny, A. (1993). Suicide prediction revisited. Suicide and LifeThreatening Behavior, Vol 23(1): 1-10.

Posner, K. et al. (2011). The Columbia-Suicide severity rating scale: initial validity and internal consistency findings from three multisite studies with adolescents and adults. American Tournal of Psychiatry; 168 (12): 1266-1277.

Powell, I. et al. (2000). Suicide in psychiatric hospital in-patients. British Journal of Psychiatry, 176: 266-272.

Rothman, K.J., Greenland, S., \& Lash, T.L. (2008). Modern epidemiology. Philadelphia: Lippincott Williams \& Wilkins.

Runeson, B. et al. (2012). Den suicidnära patienten - Värdering och handtering av suicidrisk. Lund: Studentlitteratur $A B$.

Ryle, G. (1949/1990). The concept of mind. Penguin Books.

Shaffer, I. et al. (1974). The prediction of suicide in schizophrenia. The Journal of Nervous and Mental Disease, 159 (5): 349-355.

Thorvik, A. (2011). Suicid som etisk fenomen. Teoretiske og empiriske perspektiver. Oslo: Unipub.

Vrieze, S.I. \& Grove, W.M. (2009). Survey on the use of clinical and mechanical prediction methods in clinical psychology. Professional Psychology: Research and Practice. 40 (5): 525-531.

Egirsdottir, S. et al. (2006). The meta-analysis of clinical judgment project: Fifty-six years of accumulated research on clinical versus statistical prediction. The Counseling Psychologist, Vol. 34 No. 3: 341-382.

Aarre, T.F., Hammer, I., \& Stangeland, T. Ingen kan foresjå siølvmord. Aftenposten 23. mai 2017.

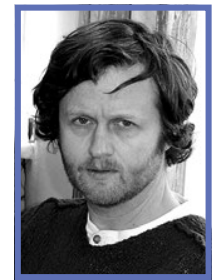

ARNE THORVIK er psykiater og avd.overlege ved Psykiatrisk fylkesavdeling ved Sykehuset Vestfold. Han disputerte for sin doktorgrad i 2011 med en avhandling bl.a. basert på dybdeintervjuer av pasienter med suicidproblematikk. Thorvik er medlem av redaksjonskomiteen ved Suicidologi. 